\title{
Endothelin-1-Induced Phosphorylation of the 20-kDa Myosin Light Chain and Caldesmon in Porcine Coronary Artery Smooth Muscle
}

\author{
Yoichiro Abe ${ }^{1}$, Yoshitoshi Kasuya ${ }^{2}$, Michiyo Kudo ${ }^{1}$, Kamejiro Yamashita ${ }^{1}$, \\ Katsutoshi Goto ${ }^{2}$, Tomoh Masaki ${ }^{2}$ and Yoh Takuwa ${ }^{1 . *}$ \\ Departments of Internal Medicine and ${ }^{2}$ Pharmacology, University of Tsukuba School of Medicine, \\ Tsukuba, Ibaraki 305, Japan
}

Received July 29, 199! Accepted September 9, 1991

\begin{abstract}
Endothelin-1 (ET), a potent vasoconstrictor, induces a sustained increase in the phosphorylation level of the $20-\mathrm{kD}$ a myosin light chain (MLC) in porcine coronary artery strips. ET also induces late phosphorylation of caldesmon, which is mimicked by 12-deoxyphorbol 13-isobutyrate, but not by $60 \mathrm{mM} \mathrm{KCl}$. Nitroglycerin, a vasorelaxant, completely reverses the ET-induced phosphorylation of MLC, but not that of caldesmon. These results suggest an important regulatory role of MLC phosphorylation in ET-induced contraction.
\end{abstract}

Endothelin-1 (ET) is one of the most potent vasoconstrictors to be discovered (1). Our previous studies $(2-4)$ as well as observations by other investigators (5) demonstrate that ET receptor activation in vascular smooth muscle leads to the activation of phospholipase $\mathrm{C}$ and $\mathrm{Ca}^{2+}$ channels, resulting in an increase in the intracellular free $\mathrm{Ca}^{2+}$ concentration and the activation of protein kinase $\mathrm{C}$. However, it is not known how ET-1 activates the contractile mechanism following the generation of the second messengers. To understand in more detail the mechanism of the ET-induced contraction of vascular smooth muscle, phosphorylation changes of the proteins thought to be involved in the regulation of contraction were explored in porcine coronary smooth muscle. Particularly, we studied the time-de-

\footnotetext{
* All correspondence should be addrcssed to: Dr. Yoh Takuwa, Department of Vascular Biology, Faculty of Medicine, University of Tokyo, 7-3-1 Hongo, Bunkyo-ku, Tokyo 113, Japan
}

pendent changes in the extent of the $\mathrm{Ca}^{2+}$ and calmodulin-dependent phosphorylation of $20-\mathrm{kDa}$ myosin light chain (MLC), which is known to serve as a specific signal for initiating cross bridge cycling (6), and phosphorylation of caldesmon, a calmodulin-binding, thin filament-associated protein $(7,8)$.

Porcine right coronary arteries were dissected and carefully cleared of adhering connective tissue $(2,4)$. Transverse arterial strips of approximately $2-\mathrm{mm}$ width were prepared for the experiments. Strips were mounted in $10-\mathrm{ml}$ static muscle chambers and equilibrated in modified Krebs-Henseleit bicarbonate buffer containing $10^{-5} \mathrm{M}$ phentolamine and $10^{-6}$ $\mathrm{M}$ atropin (9) aerated with $95 \% \quad \mathrm{O}_{2} / 5 \% \mathrm{CO}_{2}$ at $37^{\circ} \mathrm{C}$. Tension was isometrically measured with a Nihon Kohden TB-611T force-displacement transducer and displayed on a Nihon Kohden WT-647G recorder. The tension in response to agonist stimulation was expressed as a percent of the maximal response to $\mathrm{KCl}(110$ $\mathrm{mM}$ ). To measure the phosphorylation of 20 - 
kDa MLC, isometrically contracting muscle strips were rapidly frozen by immersing them in an acetone-dry ice slurry containing $10 \%$ trichloroacetic acid and $20 \mathrm{mM}$ dithiothreitol (DTT) (10). The strips were then homogenized in a homogenization buffer consisting of $10 \%$ glycerol, $20 \mathrm{mM}$ DTT, $1 \%$ sodium dodecyl sulfate (SDS), $75 \mathrm{mM} \mathrm{NaF}, 10 \mathrm{mM}$ EGTA and $10 \mathrm{mM}$ Tris/HCl $(\mathrm{pH} \mathrm{7.0)}$ ). The phosphorylated and unphosphorylated $20-\mathrm{kDa}$ MLCs were separated by two-dimensional gel electrophoresis as described previously (9). The area of each spot of MLC was determined by a Shimadzu scanning densitometer. The phosphorylation level of MLC was calculated by dividing the area of phosphorylated MLC by the total area of both phosphorylated and unphosphorylated MLC (10). For the measurements of caldesmon phosphorylation, arterial strips were labelled for a total of $4 \mathrm{hr}$ by incubating them in $1 \mathrm{ml}$ of physiological salt solution (PSS) containing $200 \mu \mathrm{Ci} / \mathrm{ml}$ $\left[{ }^{32} \mathrm{P}_{\mathrm{PO}_{4}}{ }^{3-}\right.$ of the following composition: 140 $\mathrm{mM} \mathrm{NaCl}, 4 \mathrm{mM} \mathrm{KCl}, 1 \mathrm{mM} \mathrm{MgSO}_{4}, 1.25$ $\mathrm{mM} \mathrm{CaCl}, 0.3 \mathrm{mM} \mathrm{NaH} \mathrm{PO}_{4}, 11 \mathrm{mM}$ glucose and $20 \mathrm{mM}$ Hepes ( $\mathrm{pH} 7.4)$. The strips were quickly homogenized in a homogenization buffer consisting of $0.3 \mathrm{M} \mathrm{KCl}, 2 \mathrm{mM}$ EGTA, 0.5 $\mathrm{mM} \mathrm{MgCl} 2,50 \mathrm{mM} \mathrm{NaF}, 1 \mathrm{mM}$ phenylmethylsulfonyl fluoride and $50 \mathrm{mM}$ imidazole $(\mathrm{pH}$ 6.9) (11). Caldesmon was extracted by immediate heating at $100^{\circ} \mathrm{C}$ for $5 \mathrm{~min}$, followed by the centrifugation at $47,000 \times g$ for $30 \mathrm{~min}$ (11). The resulting supernatant was analyzed by $10 \%$ SDS polyacrylamide gel electrophoresis. Caldesmon was identified by immunoblotting using anti-chicken gizzard caldesmon antibody and the comigration with purified caldesmon. The band corresponding to caldesmon was excised from the gel, and the radioactivity was counted. Statistical analysis was performed by Student's $t$-test. Statistical significance was difined as $\mathbf{P}<\mathbf{0 . 0 5}$. The values are expressed as the means \pm S.E. 12Deoxyphorbol 13-isobutyrate and endothelin-1 were purchased from LC Services (Woburn, U.S.A.) and the Peptide Institute (Osaka, Japan), respectively. All other chemicals were of reagent grade purity.

ET-1 $\left(10^{-7} \mathrm{M}\right)$ induces a gradual rise in the phosphorylation level of MLC, which reaches a peak at $5 \mathrm{~min}$ and stays at this level for at least $60 \mathrm{~min}$ in porcine coronary smooth muscle (Fig. 1). The basal phosphorylation level is $0.06 \pm 0.01 \mathrm{moles} P /$ mole MLC $(\mathbf{n}=8)$, and the plateau level (at $5 \mathrm{~min}$ ) is $0.19 \pm 0.02$ moles $\mathrm{P} /$ mole MLC $(\mathbf{n}=5)$. The isometric tension also monotonically increases toward a plateau where the tension remaines for 60 min. Either $60 \mathrm{mM} \mathrm{KCl}$ or histamine $\left(10^{-4} \mathrm{M}\right)$ induces more rapid initial rises in both the phosphorylation level of MLC and the isometric tension (Fig. 1). The phosphorylation level reaches a peak within $30 \mathrm{sec}$ in both $60 \mathrm{mM} \mathrm{KCl}$ - and histamine-stimulated coronary artery strips. In $60 \mathrm{mM} \mathrm{KCl}$-stimulated strips the phosphorylation level and the tension are nearly completely maintained during the $60 \mathrm{~min}$ period, while in the histaminestimulated strips, both parameters gradually decline for $60 \mathrm{~min}$ after the initial transient increase.

ET induces a significant increase $(42 \pm 8 \%$ increase over the basal level $(n=5)$ in the phosphorylation level of caldesmon at $60 \mathrm{~min}$, but not at $5 \mathrm{~min}$ (Fig 2, A and D). 12-Deoxyphorbol 13-isobutyrate (DPB) $\left(8 \times 10^{-7} \mathrm{M}\right)$, an active phorbol ester, also stimulates late phosphorylation of caldesmon $(76 \pm 20 \%$ increase $(n=4)$ (Fig. 2, A and D). Histamine $\left(10^{-4} \mathrm{M}\right)$ tends to stimulate phosphorylation at $60 \mathrm{~min}(0.05<\mathrm{P}<0.1)$ (Fig. 2, $\mathrm{B}$ and $\mathrm{D}$ ). However, $60 \mathrm{mM} \mathrm{KCl}$ does not have any stimulatory effect on the caldesmon phosphorylation (Fig. 2, C and D).

When nitroglycerin $\left(10^{-5} \mathrm{M}\right)$ is added to strips precontracted with ET $\left(10^{-7} \mathrm{M}\right)$ at 60 min, the strips fully relax with a complete return of the phosphorylation level of MLC to the basal level $(0.07 \pm 0.01(n=4)$ in ET and nitroglycerin-treated stirps vs. $0.06 \pm 0.01$ moles $\mathrm{P} /$ mole $\mathrm{MLC}(\mathrm{n}=4)$ in control strips) at $80 \mathrm{~min}$. However, the administration of nitroglycerin does not significantly inhibit the caldesmon phosphorylation $(48 \pm 15 \%$ increase $(n=4)$ in ET-stimulated strips vs. 30 


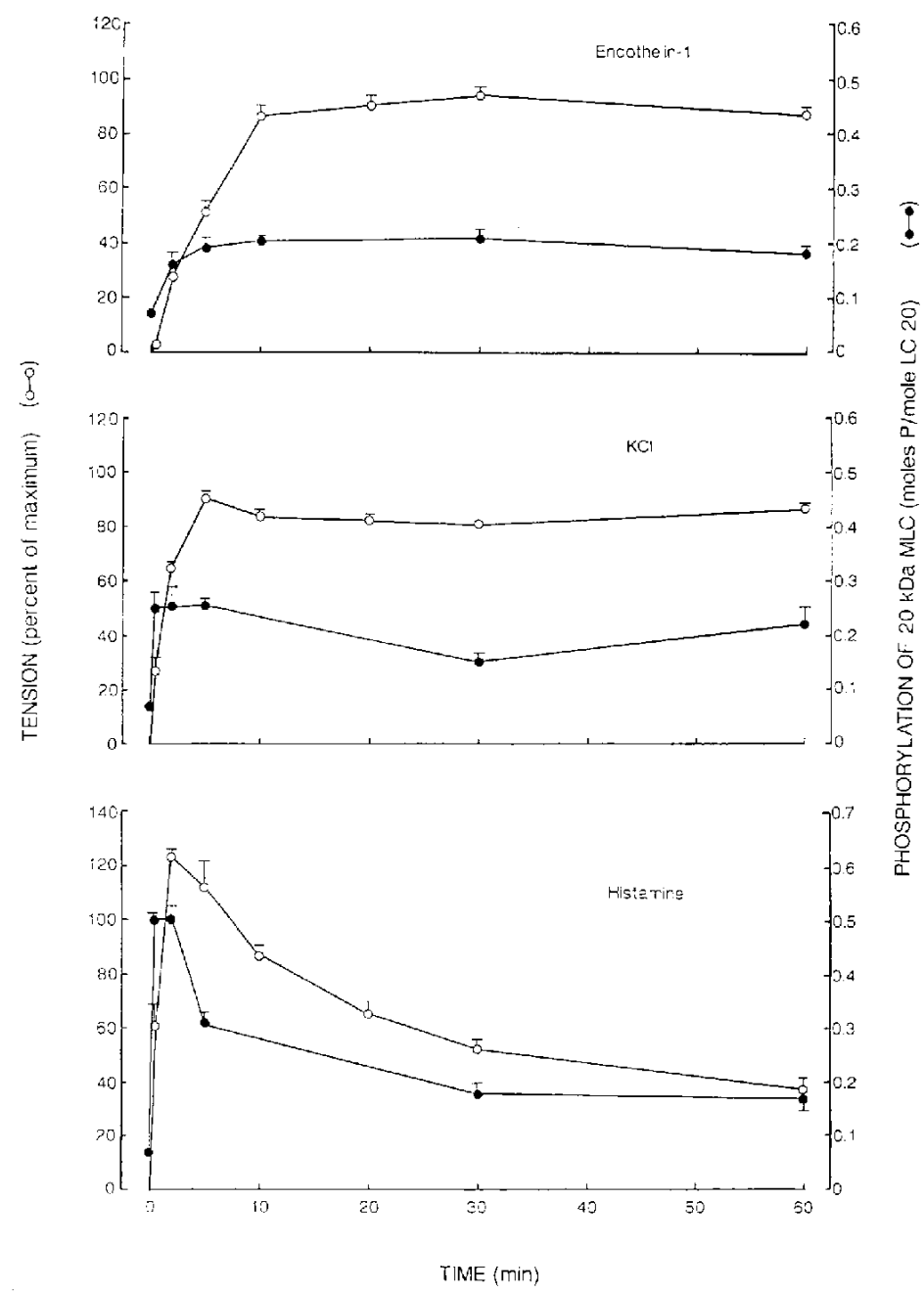

Fig. 1. Time courses of isometric tension (O) and phosphorylation of the 20 -kDa myosin light chain (O) during prolonged stimulation of porcine coronary artery strips with $10^{-7} \mathrm{M}$ endothelin-1, $60 \mathrm{mM} \mathrm{KCl}$ or $10^{-7} \mathrm{M}$ histamine. The data are the means \pm S.E. of 4 to 10 determinations. $\pm 7 \%$ increase $(\mathrm{n}=4)$ in ET and nitroglycerin-treated strips).

The present results demonstrate that ET induces a slowly developing and sustained increase in the phosphorylation level of MLC, the change of which slightly precedes but closely resembles the time course of the contractile response, in porcine coronary strips (Fig. 1). When strips precontracted with ET are induced to relax by the addition of nitroglycerin, a concomitant reduction in the phosphorylation level of MLC is found. These results indicate a close correlation between the MLC phosphorylation and the isometric ten- sion, suggesting an important regulating role of the MLC phosphorylation in the ETinduced vasoconstriction of coronary artery smooth muscle.

One characteristic of the responses of coronary strips to ET shown in the present study is initial slow kinetics in both the phosphorylation of MLC and the tension as compared to histamine and $60 \mathrm{mM} \mathrm{KCl}$. A similar initial gradual rise in the intracellular $\mathrm{Ca}^{2+}$ concentration is also found in ET-1-stimulated coronary strips (4). The molecular characterization of the initial signal transduction pathway does not clearly distinguish ET from 


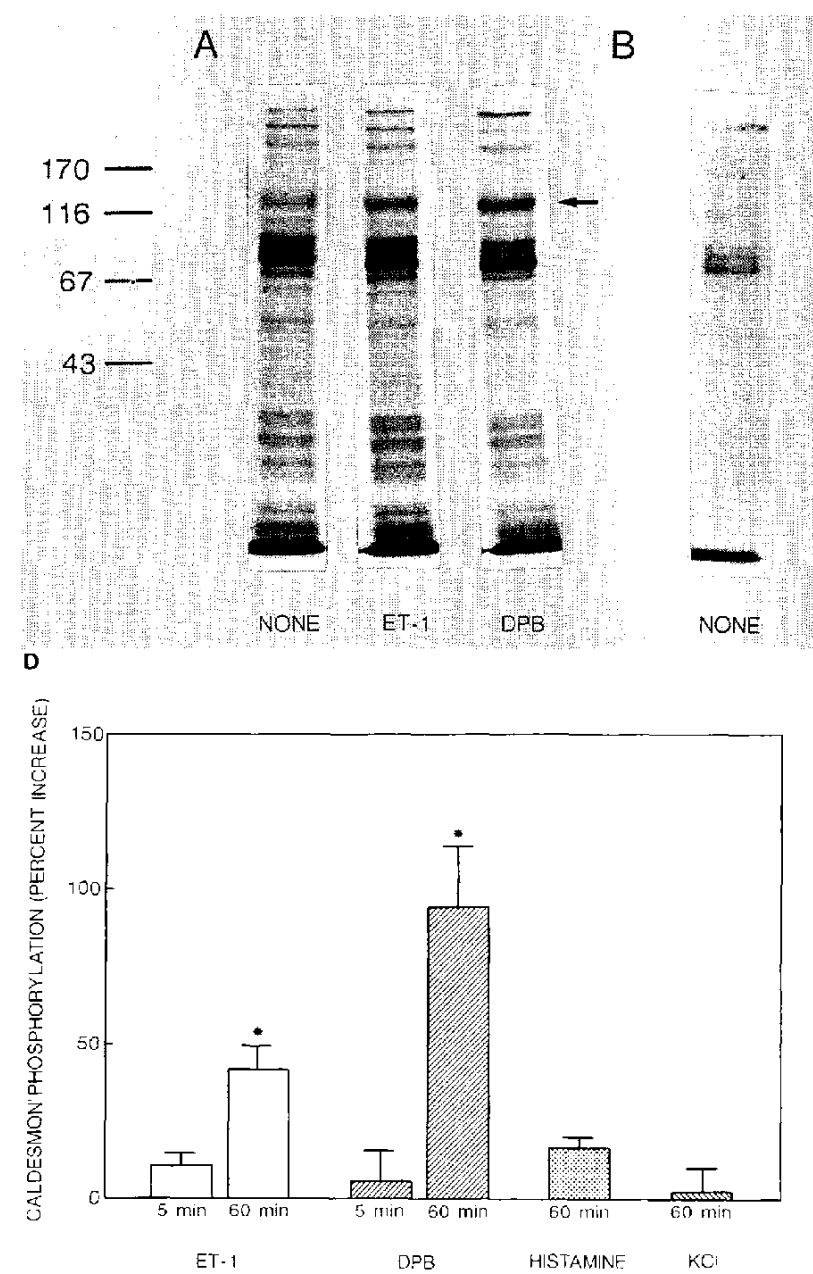

Fig. 2. Phosphorylation of caldesmon $(\mathrm{CaD})$ in porcine coronary artery strips stimulated with $10^{-7} \mathrm{M}$ ET-1, $8 \times 10^{-7} \mathrm{M}$ 12-deoxyphorbol 13-isobutyrate, $10^{-4} \mathrm{M}$ histamine or $60 \mathrm{mM} \mathrm{KCl}$. A-C: Autoradiograms of gels. Arrows denote the migration position of caldesmon (CaD). Coronary strips were stimulated for $60 \mathrm{~min}$. D: A quantitative summary of caldesmon phosphorylation. Coronary strips were stimulated for 5 or $60 \mathrm{~min}$. The data are the means \pm S.E. of 4 to 6 determinations. ${ }^{*}: P<0.05$.

other vasoactive agonists $(3,12,13)$. Further investigations are required to resolve the mechanisms for the slow kinetics of these parameters in ET-stimulated vascular smooth muscle.

The present study demonstrates that ET induces a time-dependent phosphorylation of caldesmon (Fig. 2). DPB, a protein kinase C activator, but not $60 \mathrm{mM} \mathrm{KCl}$ has a similar effect on caldesmon phosphorylation. Since ET stimulates phospholipase $\mathrm{C}$ to produce 1,2diacylglycerol, leading to protein kinase $\mathrm{C}$ activation $(2,3,5,14)$, these results suggest that ET-induced caldesmon phosphorylation may be mediated directly or indirectly through protein kinase C. Recent studies (15) sug- gested that the regulatory function of caldesmon might be altered by its phosphorylation state. Adam et al. $(8,15)$ reported that in intact porcine carotid artery stimulated with phorbol 12,13-dibutyrate (PDB), the phosphorylation level of caldesmon increased with a rather slow time course, consistent with the present results. They showed that $\mathrm{KCl}$ also stimulated caldesmon phosphorylation in the carotid artery. The reason for the difference between the present results and those by Adam et al. (8) concerning the effect of $\mathrm{KCl}$ on caldesmon phosphorylation is not known. One possible explanation is that vasoactive substances released from nerve termini in the arterial wall in response to $\mathrm{KCl}$ stimulation 
acted on smooth muscle to cause caldesmon phosphorylation because receptor antagonists were not included in the buffer in the study by Adam et al. (8).

In the present study, nitroglycerin induced a complete relaxation of ET-treated porcine coronary strips without significant dephosphorylation of caldesmon. These results suggest that if caldesmon phosphorylation is involved in the biochemical mechanism for the force maintenance of vascular smooth muscle, it is not the sole determinant. Alternatively, it might be possible that nitroglycerin inhibits the contractile mechanisms at a site distal to the phosphorylation of caldesmon. Further studies are required to reveal the functional role of caldesmon phosphorylation.

\section{Acknowledgments}

We wish to thank Dr. H. Rasmussen and Dr. Y. Nonomura for reading the manuscript and kindly donating anticaldesmon antibody, respectively. This work supported by grants from the Ministry of Science and Education in Japan, the University of Tsukuba Project Research, the Fujisawa Foundation, the Mochida Memorial Foundation for Medical and Pharmacological Research and the Kowa Foundation for Life Science.

\section{REFERENCES}

1 Yanagisawa, M., Kurihara, H., Kimura, S., Tomobe, Y., Kobayashi, M., Mitsui, Y., Yazaki, Y., Goto, K, and Masaki, T.: A novel potent vasoconstrictor peptide produced by vascular endothelial cells. Nature 332,411-415 (1988)

2 Kasuya, Y., Takuwa, Y., Yanagisawa, M., Kimura, S., Goto, K. and Masaki, T.: Endothelin1 induces vasoconstriction through two functionally distinct pathways in porcine coronary artery: contribution of phosphoinositide turnover. Biochem. Biophys. Res. Commun. 161, 1049-1055 (1989)

3 Takuwa, Y., Kasuya, Y.. Takuwa, N., Kubo, M., Yanagisawa, M., Goto, K., Masaki, T. and Yamashita, K.: Endothelin receptor is coupled to phospholipase $\mathrm{C}$ via a pertussis toxin-insensitive guanine nucleotide-binding regulatory protein in vascular smooth muscle cells. J. Clin. Invest. 85, $653-658$ (1990)

4 Goto, K., Kasuya, Y., Matsui, N., Takuwa, Y., Kurihara, H., Ishikawa, T., Kimura, S., Yanagisawa, M. and Masaki, T.: Endothelin activates the dihydropyridine-sensitive, voltage-dependent $\mathrm{Ca}^{2+}$ channel in vascular smooth muscle. Proc. Natl. Acad. Sci. U.S.A. 86, 3915-3918 (1989)

5 Resink, T.J., Scott-Burden, T, and Bühler, F.R.: Endothelin stimulates phospholipase $\mathrm{C}$ in cultured vascular smooth muscle cells. Biochem. Biophys. Res. Commun. 157, 1360)-1368 (1988)

6 Kamm, K.E. and Stull, J.T.: The function of myosin and myosin light chain kinase phosphorylation in smooth muscle cell. Annu. Rev. Pharmacol. Toxicol. 25, 593-620 (1985)

7 Sobue, K., Morimoto, K., Inui, M., Kanda, K. and Kakiuchi, S.: Control of action-myosin interaction of gizzard smooth musclc by calmodulin and caldesmon linked flip-flop mechanism. Biomed. Res. 3, 188-196 (1982)

8 Adam, L.P., Heaberle, J.R. and Hathaway, D.R.: Phosphorylation of caldesmon in arterial smooth muscle. J. Biol. Chem. 264, 7698-7703 (1989)

9 Takuwa, Y., Kelley, G., Takuwa, N. and Rasmussen, H.: Protein phosphorylation changes in bovine carotid artery smooth muscle during contraction and relaxation. Mol. Cell. Endocrinol. 60, $71-86$ (1988)

10 Jiang, M.J. and Morgan, K.G.: Agonist-specific myosin phosphorylation and intracellular calcium during isometric contraction of arterial smooth muscle. Pflügers Arch. 413, 637-643 (1989)

11 Bretscher, A.: Smooth muscle caldesmon. Rapid purification and $\mathrm{F}$-actin cross-linking properties. J. Biol. Chem. 259, 12873-12880 (1984)

12 Sakurai, T., Yanagisawa, M., Takuwa, Y. Miyazaki, H., Kimura, S., Goto, K. and Masaki, T.: Cloning of a cDNA encoding a non-isopeptideselective subtype of the endothelin receptor. Nature 348, 732 - 735 (1990)

13 Arai, H., Hori, S., Aramori, I., Ohkubo, H. and Nakanishi, S.: Cloning and cxpression of a cDNA encoding an endothelin receptor. Nature 348, 730 -732 (1990)

14 Haller, H., Smallwood, J.I. and Rasmussen, H. Protein Kinase $\mathrm{C}$ translocation in intact vascular smooth muscle strip. Biochem. J. 270, 375-381 (1990)

15 Adam, L.P., Milio, L., Brengle, B. and Hathaway, D.L.: Myosin light chain and caldesmon phosphorylation in arterial muscle stimulated with endothelin-1. J. Mol. Cell. Cardiol. 22, 1017-1023 (1990) 